\title{
Intensivpflichtige Virusinfektionen der unteren Atemwege
}

Nora Drick, Tobias Welte

Virusinfektionen der unteren Atemwege sind auf der Intensivstation häufig und können insbesondere bei Risikopatienten zu schweren Krankheitsverläufen führen. Bei diesen Fällen kann eine rasche und zielgerichtete Diagnostik und Therapie lebensrettend sein.

\section{Einleitung}

Viren machen den größten Anteil der Erreger menschlicher Infektionskrankheiten aus. Zum großen Teil sicherlich bedingt durch die zunehmend sensitivere Diagnostik nimmt auch die Zahl der nachgewiesenen Virusinfektionen auf den Intensivstationen stetig zu [1]. Respiratorische Viren sind die häufigste Ursache für akute Exazerbationen bei COPD- und AsthmaPatienten [2,3]. In Studien schwankt die Anzahl der durch Viren verursachten ambulant erworbenen Pneumonien („community acquired pneumonia“, CAP) zwischen 5 und 34\% [4]. Häufigste Ursache der viralen CAP ist eine Infektion mit Influenza-Viren.

Der überwiegende Teil viraler Infektionen der unteren Atemwege bedarf keiner Behandlung im Krankenhaus, insbesondere bei Patienten mit chronischen Grunderkrankungen kann jedoch eine stationäre Aufnahme erforderlich werden [5]. Der Großteil der Virusinfektionen, die einer intensivmedizinischen Behandlung bedürfen, betreffen die unteren Atemwege und das zentrale Nervensystem. Aber auch andere Organsysteme wie der Gastrointestinaltrakt oder die Nieren können von schweren viralen Infektionen betroffen sein. Schwere Virusinfektionen können der initiale Grund für einen Intensivaufenthalt sein oder auch eine zusätzliche Komplikation darstellen, z. B. in Form einer nosokomialen viralen Infektion. Eine besondere Bedeutung kommt den viralen Infektionen bei immunsupprimierten Patienten zu.

Aufgrund der Fülle der viralen Infektionen beschränkt sich der vorliegende Beitrag auf die wichtigsten Virusinfektionen der unteren Atemwege (Tab. 1).

\section{Pathogenese der Virusinfektion}

Viren können ganz unterschiedliche Immunantworten des Wirts hervorrufen, die für die Virusabtötung wesentliche zelluläre und humorale Prozesse initiieren. Gleichzeitig kann eine überschießende Immunantwort jedoch auch zu einer Schädigung der alveolär-kapillaren Barriere mit einer alveolären Flüssigkeitsansammlung, einer intraalveolären Fibrinakkumulation und einer weiteren Steigerung der Entzündungsreaktion durch oxidierte Phospholipide führen [6]. Eine erfolgreiche Kontrolle der Virusreplikation und der daraus resultierenden Immunantwort ist die Grundlage für die epitheliale Regeneration. 
Tabelle 1

Übersicht über die wichtigsten respiratorischen Viren.

\begin{tabular}{|c|c|c|c|c|c|}
\hline Virus & Virusfamilie & $\begin{array}{l}\text { Wichtige klinische } \\
\text { Manifestationen (ICU) }\end{array}$ & Diagnostik & Therapie & Anmerkung \\
\hline Influenza & Orthomyxoviridae & $\begin{array}{l}\text { Pneumonie, ARDS, Myo- } \\
\text { perikarditis, Rhabdomyo- } \\
\text { lyse, Enzephalitis }\end{array}$ & $\begin{array}{l}\text { Antigen- } \\
\text { Schnelltest, } \\
\text { PCR }\end{array}$ & $\begin{array}{l}\text { Oseltamivir (p. o.), } \\
\text { Zanamivir (p. i.) }\end{array}$ & $\begin{array}{l}\text { Therapiebeginn möglichst } \\
\text { innerhalb von } 48 \text { h; } \\
\text { Influenza-Impfung möglich }\end{array}$ \\
\hline $\begin{array}{l}\text { Respiratory } \\
\text { Syncytial Virus } \\
\text { (RSV) }\end{array}$ & Paramyxoviridae & $\begin{array}{l}\text { Pneumonie (unter } \\
\text { Immunsuppression) }\end{array}$ & PCR & $\begin{array}{l}\text { Ribavirin p.o. oder p.i. } \\
\text { (in seltenen Fällen) }\end{array}$ & $\begin{array}{l}\text { Risikogruppen: stammzell- } \\
\text { und lungentransplantierte } \\
\text { Patienten, UAW von Ribavi- } \\
\text { rin: Hämolyse }\end{array}$ \\
\hline $\begin{array}{l}\text { humanes } \\
\text { Metapneumovirus }\end{array}$ & Paramyxoviridae & $\begin{array}{l}\text { Pneumonie (unter } \\
\text { Immunsuppression) }\end{array}$ & PCR & $\begin{array}{l}\text { Ribavirin p.o. } \\
\text { (in seltenen Fällen) }\end{array}$ & $\begin{array}{l}\text { Risikofaktor: Immun- } \\
\text { suppression }\end{array}$ \\
\hline Coronavirus & Coronaviridae & $\begin{array}{l}\text { ARDS durch das SARS- } \\
\text { oder MERS-Coronavirus, } \\
\text { sonst milde Verläufe }\end{array}$ & PCR & symptomatisch & $\begin{array}{l}\text { Risikofaktoren für eine } \\
\text { MERS-Co-Infektion: Reisen } \\
\text { in arabische Risikogebiete }\end{array}$ \\
\hline Adenovirus & Adenoviridae & $\begin{array}{l}\text { Kolitis, Pneumonie, } \\
\text { Hepatitis, Nephritis, } \\
\text { Encephalitis }\end{array}$ & PCR & $\begin{array}{l}\text { symptomatisch, anti- } \\
\text { virale Therapie (Cidofo- } \\
\text { vir, Ganciclovir) nur bei } \\
\text { schweren Verläufen }\end{array}$ & $\begin{array}{l}\text { Risikofaktor: Organtrans- } \\
\text { plantation }\end{array}$ \\
\hline $\begin{array}{l}\text { Herpes-simplex- } \\
\text { Virus Typ } 1 \text { (HSV-1) }\end{array}$ & Herpesviridae & Pneumonie, Enzephalitis & PCR & $\begin{array}{l}\text { Aciclovir i.v. (in Nieren- } \\
\text { adaptierter Dosis) }\end{array}$ & $\begin{array}{l}\text { UAW von Aciclovir: } \\
\text { reversibles Nierenversagen }\end{array}$ \\
\hline $\begin{array}{l}\text { Zytomegalievirus } \\
\text { (CMV) }\end{array}$ & Herpesviridae & $\begin{array}{l}\text { Enzephalitis, Retinitis, } \\
\text { Hepatitis, Nephritis, } \\
\text { Kolitis, Pneumonie }\end{array}$ & $\begin{array}{l}\text { PCR, } \\
\text { pp65-Antigen- } \\
\text { Bestimmung }\end{array}$ & $\begin{array}{l}\text { Ganciclovir i.v., alterna- } \\
\text { tiv: Foscavir, Cidofovir }\end{array}$ & $\begin{array}{l}\text { UAW: Nephro- und Myelo- } \\
\text { toxizität }\end{array}$ \\
\hline
\end{tabular}

p. o.: per os, p.i.: per inhalationem, ARDS: Acute Respiratory Distress Syndrome, UAW: unerwünschte Arzneimittelwirkung, SARS: Severe Acute Respiratory Syndrome, MERS: Middle East Respiratory Syndrome

\section{Intensivpflichtige Virus- infektionen der unteren Atemwege}

Aufschluss über die Inzidenz von Virusinfektionen auf der Intensivstation geben einige Studien, in welchen die Atemwege intubierter Patienten auf respiratorische Viren untersucht wurden. Im Sputum und zum Teil in der bronchoalveolären Lavage (BAL) konnten je nach Studie bei $22-36 \%$ der Patienten mit PCR respiratorische Viren nachgewiesen werden [7-9]. Am häufigsten nachzuweisen waren humaner Rhinovirus (ca. 24\%), Respiratory Syncytial Virus (RSV bis zu 27\%), Parainfluenza-Viren (bis zu 27\%) sowie Influenza-Viren (ca. 16\%) und Herpes-simplex-Virus (HSV ca. 22\%).

Rhinoviren, RSV, Parainfluenza- und InfluenzaViren gehören zu den am häufigsten bei Patienten auf der Intensivstation nachgewiesenen Viren.
Als Risikofaktoren für einen Virusnachweis der unteren Atemwege wurden pulmonale Vorerkrankungen, Immunsuppression sowie die kühle Jahreszeit identifiziert. An eine Viruserkrankung sollte man insbesondere bei Nichtansprechen auf eine antibiotische Therapie, einer erneuten klinischen Verschlechterung im Verlauf sowie bei Vorliegen der genannten Risikofaktoren denken.

\section{Influenza}

Erreger. Für den Menschen pathogen sind die Influenza-A- und -B-Viren. Anhand der Glykoproteine Hämagglutinin (HA) und Neuraminidase (NA), die sich auf der Virusoberfläche befinden, können die Influenza-A-Viren weiter in Subtypen unterteilt werden. Bis zu der großen Influenza-Pandemie 2009 zirkulierten neben der Influenza B die Subtypen A(H1N1) und A(H3N2). Seit April 2009 verbreitet sich zudem das 
pandemische Influenzavirus A(H1N1)2009, das einen bis dahin unbekannten Subtyp der Influenza A(H1N1) darstellte, der zwar die klassischen Eigenschaften einer Influenza A(H1N1) aufwies, allerdings außerhalb der typischen Influenzasaison auftrat. Influenza-Erkrankungen treten überwiegend saisonal auf und spielen auf den Intensivstationen im Winter und während der Influenza-Pandemien eine große Rolle. Während von den saisonalen Influenza-Wellen insbesondere ältere Patienten über 60 Jahre betroffen sind [10], führen die zirkulierenden Virustypen während einer Pandemie häufiger auch bei jüngeren Patienten zu schweren Krankheitsverläufen [11]. Als Prophylaxe steht die Influenza-Impfung zur Verfügung. Eine niedrige Influenza-Impfrate ist verbunden mit einer steigenden Zahl stationärer Aufnahmen auf die Intensivstation [12].

Prophylaxe. Eine Besonderheit der Influenza-Viren ist ihre große genetische Variabilität mit einer hohen Mutationsfrequenz. Häufig auftretende Punktmutationen führen nach und nach zu einer Antigendrift. Durch die Driftvarianten können die Viren mit leicht veränderten Oberflächenproteinen saisonale Influenzawellen auslösen. Ein Antigenshift entsteht durch den Austausch von Gensegmenten oder solche Mutationen, die die Antigen-Eigenschaften erheblich verändern. Die so entstehenden Subtypen weichen erheblich von den bisherigen Viren ab und sind die Auslöser schwerwiegender Influenza-Pandemien. Aufgrund dieser genetischen Variabilität ist es erforderlich, den Influenza-Impfstoff jährlich an die zirkulierenden Subtypen anzupassen. Von der Ständigen Impfkommission (STIKO) empfohlen wird die Impfung für folgende Risikogruppen:

- Personen ab 60 Jahre

- Schwangere ab dem zweiten Trimenon (bei bestehendem Grundleiden ab dem ersten Trimenon)

- Personen mit erhöhtem Risiko durch ein Grundleiden (u. a. COPD, Asthma, chronische Herz-, Kreislauf-, Nieren-, Lebererkrankungen, neurologische Erkrankungen)

- immunsupprimierte Patienten

- medizinisches Personal

- Personen, die in Bereichen mit umfangreichem Publikumsverkehr beschäftigt sind

Zu beachten ist, dass der volle Impfschutz erst 2 Wochen nach der Impfung eintritt. Eine Infektion direkt nach der Impfung ist daher möglich. Dennoch gehört die Influenza-Impfung zu den sehr wirksamen präventiven Maßnahmen $[14,15]$.
Klinik. Gefürchtet sind bei der Influenza schwere Verläufe, die über die Pneumonie bis zum ARDS (Acute Respiratory Distress Syndrome) fortschreiten und einen passageren Organersatz mit venovenöser extrakorporaler Membranoxygenierung (vv-ECMO) erforderlich machen können. Die Beteiligung anderer Organsysteme im Rahmen einer Myositis oder Myokarditis ist möglich [13]. Auch an eine bakterielle Superinfektion sollte man bei schwerwiegenden Verläufen unbedingt denken.

Diagnostik. Bei schweren Verläufen ist eine schnelle Diagnostik hilfreich. Hierzu stehen Methoden zum Nachweis viraler Antigene zur Verfügung, die eine hohe Sensitivität aufweisen, bei negativem Testergebnis eine Influenza-Infektion allerdings nicht ausschließen. Daher ist bei schweren Krankheitsverläufen eine VirusPCR erforderlich, die somit weiterhin den Goldstandard nicht nur der Influenza-Diagnostik, sondern insgesamt der Diagnostik bei Infektionen mit respiratorischen Viren darstellt. Zu beachten ist, dass die Wahrscheinlichkeit eines positiven Influenza-Nachweises nach 2 Tagen rasch abfällt [16] und auch der Qualität des Probenmaterials eine entscheidende Rolle zukommt. Die Dauer der Infektiosität beträgt im Mittel 4-5 Tage, daher wird eine Isolierung von betroffenen Patienten über einen Zeitraum von 7 Tagen empfohlen [14]. Zu beachten ist allerdings, dass die Dauer der Infektiosität bei immunsupprimierten Patienten signifikant verlängert ist [17].

Therapie. Die Wirksamkeit einer spezifischen antiviralen Therapie bei Influenza ist nach wie vor umstritten. Aktuelle Meta-Analysen konnten jedoch zeigen, dass der frühzeitige Einsatz von Oseltamivir die Krankheitsdauer verkürzen kann $[18,19]$.

Neuraminidasehemmer (Oseltamivir, Zanamivir)

können die Krankheitsdauer bei Influenza-Erkran-

kungen verkürzen.

Ob der Einsatz von Neuraminidasehemmern auch eine positive Auswirkung auf die Rate schwerer Komplikationen und das Outcome der Erkrankung hat, ist weiterhin ungeklärt und wird kritisch diskutiert $[18,20]$. Dennoch sollte man bei schweren Verläufen sowie Risikopatienten eine antivirale Therapie mit Neuraminidasehemmern (Oseltamivir, Zanamivir) erwägen. Oseltamivir wird oral und bei Bedarf auch als Suspension über eine Sonde verabreicht, wohingegen Zanamivir nur für die Inhalation zur Verfügung steht. Resistenzen gegen Oseltamivir sind selten, kommen aber vor. Da die aktuelle Resistenzlage von den zirkulieren- 
den Virustypen abhängt, ist es sinnvoll, sich während der Influenzasaison über die aktuelle Resistenzlage zu informieren. Der Einsatz des M2-Kanalblockers Amantadin wird aufgrund einer hohen Resistenzlage - vor allem gegen pandemische $\mathrm{A}(\mathrm{H} 1 \mathrm{~N} 1)$ 2009-Viren - nicht mehr empfohlen [14]. Von entscheidender Bedeutung bei der spezifischen antiviralen Therapie ist ein frühzeitiger Beginn. Die Therapie sollte möglichst innerhalb der ersten 48 Stunden nach den ersten Symptomen beginnen.

Die Therapie mit Neuraminidasehemmern sollte innerhalb der ersten 48 Stunden nach dem Auftreten der ersten Symptome beginnen.

Ein späterer Therapiebeginn hat laut der aktuellen Datenlage weniger Aussicht auf einen klinischen Effekt, ist aber in Anbetracht fehlender Alternativen gerechtfertigt.

Vor dem Hintergrund einer überschießenden Immunreaktion wird bei Influenza-Pneumonien auch der Einsatz von Kortikosteroiden häufig diskutiert. Untersuchungen konnten jedoch keinen Benefit einer Kortikosteroidtherapie nachweisen. Einige Daten zeigen sogar, dass die Rate bakterieller Superinfektionen unter Kortikosteroidtherapie deutlich zunimmt [21]. Auch die Studien bei den schweren Pneumonien bis zum akuten Lungenversagen (ARDS) konnten keinen positiven Effekt nachweisen [22]. Allerdings handelt es sich bei den Studien zum Einsatz von Kortikosteroiden bei der H1N1-Pandemie nur um Beobachtungsstudien, wobei weder die Dosis noch der Zeitpunkt der Steroidgabe oder die Länge der Therapie standardisiert waren. Dennoch gibt es aktuell keine Empfehlung für eine Kortikosteroidtherapie bei der Influenza-Pneumonie.

\section{Respiratory Syncytial Virus}

Erreger. Ähnlich wie die Influenza-Infektion treten auch Infektionen mit Respiratory Syncytial Virus (RSV) auf der Intensivstation zyklisch auf (vor allem zwischen November und April). Das RSV ist einer der bedeutendsten Erreger respiratorischer Infektionen bei Säuglingen und Kleinkindern, kann allerdings auch im Erwachsenenalter zu schweren Atemwegsinfektionen führen.

Klinik. Vor allem ältere Patienten mit kardiopulmonalen Vorerkrankungen - insbesondere Asthma bronchiale - sowie immunsupprimierte Patienten vornehmlich nach Stammzell- und Lungentransplan- tation - gelten als Risikogruppe für eine schwere RSV-Pneumonie [23].

Schwere Verläufe nach RSV-Infektion treten insbesondere bei stammzell- und lungentransplantierten Patienten auf.

Diagnostik. Zur Sicherung der Diagnose sollte man im intensivmedizinischen Bereich einen Genomnachweis mit PCR durchführen, um einer Verbreitung des Erregers schnell entgegenzuwirken.

Therapie. Die Therapie der RSV-Infektion ist überwiegend supportiv. Als antivirale Therapie steht zurzeit lediglich das Nukleosidanalogon Ribavirin zur Verfügung. In einigen wenigen Studien mit geringen Fallzahlen führte der frühe Einsatz von inhalativ verabreichtem Ribavirin bei Patienten nach hämatopoietischer Stammzelltransplantation zu einer Reduktion der RSV-bedingten Letalität [24]. Somit kann man eine Ribavirin-Therapie auch in Anbetracht der fehlenden Alternativen bei dieser Patientengruppe erwägen. Bei lungentransplantierten Patienten gilt eine RSV-Infektion als möglicher Risikofaktor für eine Abstoßungsreaktion [25]. Einzelne Studien zeigten, dass eine Ribavirin-Therapie zu einer verkürzten Krankheitsdauer und einem geringeren Risiko für eine chronische Abstoßungsreaktion führt [26]. Daher kommt Ribavirin in oraler Form bei lungentransplantierten Patienten zum Einsatz. Ergebnisse randomisierter und kontrollierter Studien liegen zurzeit jedoch nicht vor.

Die Therapie mit Ribavirin bei lungentransplantierten Patienten kann möglicherweise das Risiko einer chronischen Abstoßungsreaktion nach RSV-Infektion senken.

Als wichtige unerwünschte Arzneimittelwirkung kann es unter einer Ribavirin-Therapie zu einer hämolytischen Anämie kommen, die eine Dosisreduktion oder die Beendigung der Therapie erforderlich machen kann.

Palivizumab, ein monoklonaler Antikörper gegen das RS-Virus, wird derzeit nur prophylaktisch bei Kindern mit dem Risiko einer schwer verlaufenden RSV-Infektion eingesetzt. Untersuchungen an erwachsenen, stammzelltransplantierten Patienten haben keinen Therapieerfolg erbracht, sodass der Einsatz von Palivizumab bei erwachsenen Patienten nicht empfohlen wird [27]. Aktuell befinden sich neue RSV-Therapien in der klinischen Entwicklung, sodass für die nächsten Jahre Änderungen zu erwarten sind. 


\section{Humanes Metapneumovirus}

Erreger. Das ebenfalls aus der Gruppe der Paramyxoviren stammende humane Metapneumovirus ist dem RS-Virus in Bezug auf Übertragung und Pathogenität als Erreger von Atemwegsinfektionen sehr ähnlich. Das humane Metapneumovirus ist gleichfalls ein häufiger Erreger von Atemwegsinfektionen im frühen Kindesalter, tritt zyklisch auf und sollte insbesondere auch bei immunsupprimierten und älteren Patienten differenzialdiagnostisch in Betracht gezogen werden [28].

Klinik. Die Inzidenz der Infektionen mit humanem Metapneumovirus bei immunsupprimierten Patienten ähnelt der von immunkompetenten Patienten, die Krankheitsverläufe sind jedoch häufig schwerwiegender [29].

Diagnostik. Humane Metapneumoviren lassen sich nur sehr begrenzt in der Zellkultur anzüchten, daher ist auch hierbei die PCR die Nachweismethode der Wahl.

Therapie. Die Therapie der Atemwegsinfektion gleicht der beim RS-Virus, denn sie ist supportiv und orientiert sich am Schweregrad der klinischen Symptomatik. Invitro-Daten zeigen auch für die Infektion mit humanem Metapneumovirus eine Wirksamkeit von Ribavirin. Im Mausmodell konnte Ribavirin die Virusreplikation reduzieren [30]. Kleine Studien und Fallberichte legen den Verdacht nahe, dass auch bei immunsupprimierten Patienten mit einer Ribavirin-Therapie ein positiver Effekt auf den Krankheitsverlauf zu erzielen ist.

\section{Coronavirus}

Coronaviren sind häufige Erreger von meist mild und selbstlimitierend verlaufenden Atemwegsinfektionen. Vermutlich sind humane Coronaviren für bis zu 20-30\% der ambulant erworbenen Atemwegsinfektionen verantwortlich, ihre Pathogenität ist in der Regel gering.

\section{SARS-Coronavirus}

Erreger. Zunehmend in den Fokus der Öffentlichkeit gerückt ist das SARS-Coronavirus (SARS-CoV), als es 2002/2003 anfänglich im asiatischen Raum zum schweren akuten respiratorischen Syndrom (Severe Acute Respiratory Syndrome, SARS) führte. Bei dem Erreger handelte es sich um eine bis dahin unbekannte Variante des Coronavirus. Er entstammt höchstwahrscheinlich einem tierischen Reservoir. Ein vorläufiges
Ende fand die SARS-Epidemie nach einem kontinuierlichen Rückgang der Neuinfektionen im Sommer 2003.

Klinik. Klinisch ist das SARS durch einen akuten Krankheitsbeginn mit Fieber, Myalgien, Kopfschmerzen und schwerem Krankheitsgefühl gekennzeichnet, erst im Verlauf kommen respiratorische Symptome wie trockener Husten und Dyspnoe bis zum Atmungsversagen hinzu [31].

Respiratorische Symptome können beim SARS zeitlich verzögert auftreten.

Einer intensivmedizinischen Behandlung und einer invasiven Beatmung bedurfte es während der SARSPandemie in 20-30\% der Fälle. Die Letalität war hoch und lag zwischen 13 und 43\%, je nach Alter und Risikofaktoren [33]. Zum Tod führte in den meisten Fällen ein ARDS mit Multiorganversagen. Sehr schwere Verläufe zeigten sich gehäuft bei älteren Patienten, beim Auftreten von atypischen Symptomen sowie bei Patienten, die initial eine erhöhte Laktatdehydrogenase aufwiesen.

Als prognostisch ungünstig erwiesen sich ein höheres Patientenalter, das Auftreten von atypischen Symptomen sowie eine initial erhöhte Laktatdehydrogenase.

Mildere Verläufe hingegen kamen häufiger bei Kindern vor [34]. Die Inkubationszeit des SARS beträgt 2-7 Tage. Während der Pandemie entwickelten 95\% der betroffenen Patienten innerhalb von 10 Tagen nach Kontakt mit einer infizierten Person Symptome, daher sollte man Betroffene nach Exposition für diesen Zeitraum überwachen [35].

Diagnostik. Besteht der Verdacht auf eine SARS-Coronavirus-Infektion, sollte eine PCR-Untersuchung aus 2 Proben durchgeführt werden. Geeignete Proben sind Material aus den Atemwegen, Serum bzw. Plasma oder Stuhlproben, wobei unklar ist, welches Material in welchem Krankheitsstadium die höchste Aussagekraft hat. Auch die serologische Bestimmung von Antikörpern ist möglich, allerdings ist zu beachten, dass es in einigen Krankheitsfällen von einer zeitlich verzögerten Serokonversion bis zum völligen Fehlen nachweisbarer Antikörpertiter kommen kann. Hohe Virustiter gehen mit einer schlechteren Prognose einher [36].

Therapie. Die Therapie des SARS ist supportiv. Während der SARS-Pandemie wurden zahlreiche Patienten mit hoch dosierten Kortikosteroiden und Ribavirin 
behandelt. Einen Vorteil zeigte die Therapie nicht, dafür kam es gehäuft zu Nebenwirkungen, sodass beide Therapien nicht empfohlen werden [32].

\section{MERS-Coronavirus}

Erreger. Eine weitere neuartige Coronavirus-Infektion trat 2012 in Saudi-Arabien auf. Bei einem Patienten, der mit Pneumonie und akutem Nierenversagen ins Krankenhaus eingeliefert wurde, wurde aus dem Sputum das Middle East Respiratory Syndrome Coronavirus (MERS-Co) isoliert.

Klinik. Eine MERS-Co-Infektion beginnt meist mit grippeähnlichen Symptomen und kann im Verlauf über eine Pneumonie bis zum ARDS führen [37]. Häufige Begleitsymptome sind gastrointestinale Beschwerden, vor allem Diarrhöen, sowie ein akutes Nierenversagen. Milde bis asymptomatische Verlaufsformen sind beschrieben, zu schweren Verläufen kommt es überwiegend bei Patienten mit chronischen Vorerkrankungen wie z.B. malignen Grunderkrankungen oder Diabetes mellitus. Die Letalität ist hoch. Eine Analyse von 47 bestätigten MERS-Fällen zeigte, dass $89 \%$ der Patienten intensivmedizinisch versorgt und $72 \%$ beatmet werden mussten [38]. Als sehr wahrscheinlich gilt, dass Dromedare die Quelle für die zoonotischen Infektionen sind, obwohl auch eine Übertragung von Mensch zu Mensch möglich ist, wie sich bei einigen MERS-Co-Ausbrüchen in Krankenhäusern zeigte [37]. Risikofaktoren für die Infektion mit dem MERS-Coronavirus sind somit zum einen der Kontakt mit Dromedaren oder Kamelen, zum anderen Reisen in arabische Risikogebiete.

Bei Reisenden aus den arabischen Risikogebieten muss man bei entsprechender Klinik an eine MERSCoronavirus-Infektion denken.

Diagnostik. Empfehlungen zum weiteren Vorgehen bei Verdacht auf eine MERS-Infektion geben die Internetseiten der Weltgesundheitsorganisation (WHO) und des Center for Disease Control and Prevention (CDC). Proben für die empfohlene Diagnostik mit RT-PCR sollten vorzugsweise aus den unteren Atemwegen (Trachealsekret, BAL) gewonnen werden. Empfohlen werden ebenfalls diagnostische Verlaufskontrollen zur Sicherung der Viruselimination.

Therapie. Auch die Therapie der MERS-Infektion ist rein supportiv. In vitro als auch in Tierversuchen an Rhesus-Affen konnte die Virus-Replikation durch eine Kombinationstherapie aus Interferon- $\alpha 2 b$ und Ribavirin gehemmt werden [39]. Retrospektive Studien zei- gen für die Kombinationstherapie aus Interferon und Ribavirin beim Menschen mit MERS-Infektion jedoch sehr widersprüchliche Ergebnisse [40, 41]. Ein klarer Überlebensvorteil ergab sich nicht, sodass aktuell keine Empfehlung für die Therapie mit Interferon und Ribavirin besteht. Die Ergebnisse weiterer Studien sind abzuwarten.

\section{Adenovirus}

Erreger. Die humanpathogenen Adenoviren sind eine große Gruppe genetisch unterschiedlicher Viren. Derzeit sind über 50 Subtypen bekannt, die sich in ihrer Virulenz deutlich unterscheiden.

Klinik. Adenovirusinfektionen treten ganzjährig auf und verlaufen bei immunkompetenten Personen meist selbstlimitierend. Zu schweren Infektionen, die eine intensivmedizinische Versorgung erforderlich machen können, kommt es hauptsächlich bei immunsupprimierten Patienten. Nach hämatopoetischer Stammzelltransplantation können Infektionen mit Adenoviren zu verschiedensten Erkrankungsbildern, u.a. einer Kolitis, Pneumonie, Hepatitis, Nephritis, Enzephalitis oder einer disseminierten Infektion führen [42]. Nach Transplantation eines soliden Organs ist meist das Transplantat betroffen. So ist die seltene AdenovirenPneumonie eine frühe Komplikation nach Lungentransplantation und tritt hierbei insbesondere im Kindesalter auf. In einer Studie wurden 308 lungentransplantierte Patienten untersucht, 4 von ihnen entwickelten eine schwere Adenoviren-Pneumonie, 3 davon waren Kinder [43].

Diagnostik. Die Diagnostik richtet sich nach dem Probenmaterial und der Verdachtsdiagnose. Zur Verfügung stehen die kulturelle Anzüchtung, die PCR, die Serologie und Antigennachweise. Eine solche Diagnostik sollte man bei schweren Verläufen und einer Therapiekonsequenz durchführen.

Therapie. Eine antivirale Therapie sollte aufgrund der unzureichenden Datenlage und der ausgeprägten medikamentösen Nebenwirkungen immunkompromittierten Patienten mit schweren Krankheitsverläufen vorbehalten bleiben. Zur antiviralen Therapie setzt man Cidofovir ein, kontrollierte und randomisierte Studien zum Einsatz bei Adenovirusinfektionen gibt es allerdings nicht. In-vitro-Daten zeigen eine stärkere Reduktion der Viruslast durch Cidofovir im Vergleich zu Ganciclovir. Beobachtungsstudien sowie einzelne Fallberichte bei stammzell- oder lungentransplantier- 
ten Patienten legen den Verdacht nahe, dass eine Cidofovir-Therapie die Erkrankungsdauer verkürzen und möglicherweise auch die Letalität der schweren Adenovirusinfektion senken kann $[44,45]$. Zu beachten ist aber insbesondere die ausgeprägte dosisabhängige Nephrotoxizität.

\section{Herpes-simplex-Virus Typ 1}

Erreger. Herpes-simplex-Virus Typ 1 (HSV-1) kann bei einer Vielzahl der Patienten auf Intensivstationen im oberen Respirationstrakt nachgewiesen werden $[9,46$, 47]. Eine Reaktivierung von HSV-1 kann vorwiegend bei immunsupprimierten Patienten zu schweren Erkrankungsbildern führen.

Klinik. Fälle von HSV-Pneumonien wurden gehäuft beschrieben nach Organtransplantation, bei malignen Grunderkrankungen, nach Verbrennungen sowie bei schwangeren Frauen. Es gibt jedoch auch Fälle, in denen HSV-Pneumonien bei immunkompententen Personen auftraten, sodass HSV insbesondere bei therapierefraktären Pneumonien als Erreger in Betracht gezogen werden sollte [48]. Der genaue Mechanismus der Reaktivierung ist unklar, vermutet wird jedoch, dass die Viren durch Mikroaspirationen vom oberen Respirationstrakt, wo sie in den dortigen Ganglien latent verbleiben, in den unteren Respirationstrakt gelangen. Eine Schädigung der Mukosa durch die endotracheale Intubation und die anschließende mechanische Beatmung scheinen als mechanischer Reiz für die Reaktivierung eine Rolle zu spielen [47].

Mechanische Reize durch Intubation und

Beatmung begünstigen die Reaktivierung von

Herpes-simplex-Viren.

Wie häufig ein positiver HSV-Nachweis mit einer klinisch relevanten Erkrankung einhergeht und ob die Reaktivierung häufig einfach als Indikator für die Schwere der Grunderkrankung zu werten ist, ist nach wie vor ungeklärt. Sicher ist jedoch, dass ein HSVNachweis mit einer erhöhten Mortalität, einer längeren Beatmungsdauer und einem längeren Aufenthalt auf der Intensivstation einhergeht $[49,50]$

Diagnostik. Beim Verdacht auf eine HSV-Pneumonie sollte man eine Bronchoskopie mit BAL durchführen. Hinweise auf eine HSV-Infektion kann schon eine erosiv-entzündliche Schleimhaut geben. Dem Nachweis der Virus-DNA dient die PCR.
Therapie. Für die Therapie steht als Mittel der ersten Wahl Aciclovir zur Verfügung. Aufgrund der schlechten oralen Bioverfügbarkeit sollte man es bei schweren Infektionen parenteral verabreichen $(10 \mathrm{mg} / \mathrm{kgKG}$ alle 8 Stunden). Da die Gabe von Aciclovir zu Nierenfunktionseinschränkungen führen kann, ist eine Dosisanpassung bei Niereninsuffizienz erforderlich. Ein durch Aciclovir verursachtes akutes Nierenversagen ist in der Regel reversibel.

\section{Zytomegalievirus}

Erreger. Das Zytomegalievirus (CMV) gehört ebenfalls zur Familie der Herpesviren und hat ebenfalls die Eigenschaft, nach der Primärinfektion latent im Körper zu verbleiben. Daher ist es auch beim Zytomegalievirus wichtig, zwischen einer CMV-Infektion und einer klinisch relevanten CMV-Erkrankung mit klinischen Symptomen zu unterscheiden. Der Durchseuchungsgrad in der Bevölkerung ist hoch und so gehört auch das Zytomegalievirus zu den häufig nachgewiesenen Viren auf Intensivstationen [51].

Klinik. Die klinische Relevanz einer CMV-Erkrankung ist bei immunsupprimierten Patienten belegt [52]. Insbesondere bei HIV-Infektionen und nach Organtransplantation kann es zu einer CMV-Reaktivierung kommen, die sich klinisch u.a. als Enzephalitis, Retinitis, Hepatitis, Nephritis, Kolitis oder Pneumonie manifestieren kann.

Diagnostik. Zur Diagnostik einer CMV-Infektion ist insbesondere bei transplantierten Patienten neben der PCR der quantitative Nachweis des pp65-Antigens in Lymphozyten möglich. Ein erneuter Anstieg des pp65Antigens signalisiert eine aktive Vermehrung des Virus. Nach Beginn einer antiviralen Therapie sollte das pp65 als Zeichen eines Therapieansprechens abfallen. $\mathrm{Zu}$ beachten ist, dass die Aussagekraft des Tests bei

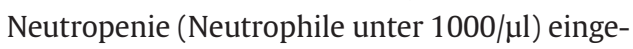
schränkt ist [53].

Die Aussagekraft der pp65-Antigen-Bestimmung

ist bei Neutropenie eingeschränkt.

Therapie. Für die Therapie der schweren CMV-Infektion steht als Medikament primär Ganciclovir zur i.v. Gabe zur Verfügung. Kommt es aufgrund einer GanciclovirResistenz zu einem Therapieversagen, können als Alternativen Foscavir oder Cidofovir eingesetzt werden. Bei allen 3 Substanzen ist auf die nephrotoxischen Nebenwirkungen zu achten und ggf. die Dosis anzu- 
passen. Ganciclovir und Foscavir sind zudem myelotoxisch [54]. Unter der Therapie sollte man mindestens einmal wöchentlich die Viruslast mit PCR oder über pp65-Antigen bestimmen.

\section{Diagnostik}

Insbesondere bei immunsupprimierten Patienten und während der Influenza-Saison sollte man bei entsprechender klinischer Symptomatik stets an eine VirusErkrankung denken (Infobox 1). Für die Diagnostik stehen prinzipiell direkte und indirekte Nachweismethoden zur Verfügung.

\section{Infobox 1}

Indikationen für eine Virusdiagnostik

- unklare Infektionserkrankung mit fehlendem Ansprechen auf eine Antibiotikatherapie

- passende Klinik während der Influenza-Saison

- Patienten mit Risikofaktoren (u. a. Immunsuppression, prädisponierende Grunderkrankung)

Indirekter Virusnachweis. Der indirekte Virusnachweis mit Antikörper-Serologie spielt für die schnelle und sensitive Diagnostik im klinischen Alltag keine Rolle mehr. Dieses Verfahren wird nur noch im Rahmen epidemiologischer Studien eingesetzt.

Direkter Virusnachweis. Hierzu steht zum einen die Isolierung mit Viruskultur zur Verfügung, die für alle vorgestellten Viren möglich ist. Aufgrund des technischen Aufwands und der langen Dauer findet sie in der Praxis jedoch kaum mehr Verwendung. Von klinischer Relevanz ist hingegen der direkte Virusnachweis über virale Antigene. Sowohl für Influenza-Viren als auch für das RS-Virus stehen Methoden zum Antigennachweis zur Verfügung (Schnelltest, ELISA, direkte Immunfluoreszenz). Aufgrund der höheren Sensitivität setzt sich die PCR mehr und mehr als Goldstandard durch.

Bei schweren Verläufen auf der Intensivstation und insbesondere bei therapierelevanten Influenza-

Viren ist ein sensitiver Erregernachweis unabdingbar [55].

Material. Geeignete Proben für die Diagnostik sollten möglichst aus den tiefen Atemwegen stammen (induziertes Sputum, Trachealsekret, BAL). Ist dies nicht möglich, können auch Rachenspülwasser sowie Nasenoder Rachenabstriche untersucht werden.

Radiologie. Radiologisch stellt sich die Viruspneumonie nicht einheitlich dar. Von einem blanden Röntgenbild über diffuse interstitielle Verdichtungen und noduläre Veränderungen, insbesondere bei immunsupprimierten Patienten, bis zur „white lung“ beim ARDS kann alles auftreten [56].

\section{Bakterielle Superinfektion}

Bei Patienten mit einer Virusinfektion der unteren Atemwege ist eine bakterielle Superinfektion wahrscheinlich, wenn einer der folgenden beiden Befunde auftritt:

- erneuter Anstieg der Infektionsmarker, insbesondere des Prokalzitonins

- weitere klinische Verschlechterung, insbesondere progrediente Gasaustauschstörungen

In diesem Fall ist zügig eine weiterführende Diagnostik zum Erregernachweis erforderlich mit Blutkulturen und der Gewinnung von Atemwegsmaterial (Sputum, Trachealsekret, BAL). Die zusätzliche Bestimmung des Pneumokokken-Antigens im Urin ist möglich, gehört jedoch nicht zur erforderlichen Standarddiagnostik, da Streptococcus pneumoniae von der initialen kalkulierten antibiotischen Therapie in jedem Fall erfasst werden muss.

Nach erfolgter Diagnostik sollte man zügig eine kalkulierte Antibiotikatherapie einleiten. Die häufigsten Erreger einer bakteriellen Superinfektion bei viralen Infekten der unteren Atemwege sind Pneumokokken und Staphylokokken [57]. Diese Erreger muss man bei der Wahl der initialen Antibiotikatherapie in jedem Fall berücksichtigen. Insbesondere auf Intensivstationen rücken gerade bei längeren stationären Aufenthalten und invasiver Beatmung die gramnegativen Bakterien (u.a. Pseudomonas aeruginosa, Klebsiella pneumoniae, Acinetobacter baumanii) zunehmend in den Vordergrund [58]. Ein größer werdendes Problem der medikamentösen Therapie sind auch die multiresistenten gramnegativen Bakterien [59].

Die häufigsten Erreger bakterieller Superinfektionen im Bereich der unteren Atemwege sind Pneumokokken und Staphylokokken. 


\section{Acute Respiratory Distress Syndrome (ARDS)}

Klinik. Zu den möglichen Symptomen einer schweren Virusinfektion der Atemwege zählen neben Husten und Dyspnoe auch hohes Fieber, Verwirrtheit, Brustschmerzen oder eine Zyanose bis zur respiratorischen Insuffizienz mit Hypoxämie und/oder Hyperkapnie. Insbesondere bei den Influenza-Viren kann es anfangs auch zu atypischen Beschwerden wie Übelkeit oder Bauchschmerzen kommen. Die schwerste Ausprägung der pulmonalen Manifestation ist das Acute Respiratory Distress Syndrome (ARDS). Ein ARDS liegt vor, wenn die Kriterien der Berlin-Definition erfüllt sind (Tab.2).

Epidemiologie. Informationen zu Inzidenz und Letalität des ARDS liefert das ARDS-Netzwerk Deutschland. Eine Analyse der Influenza-Saison 2012/2013 ergab, dass in den teilnehmenden Zentren 102 Influenza-Patienten mit einem ARDS auf der Intensivstation behandelt werden mussten. Die Letalität lag im Gesamtkollektiv bei 38\%. Bei den Patienten, die das invasive Verfahren der extrakorporalen Membranoxygenierung (ECMO) benötigten, lag sie bei 54\% [60].

Therapie. Ein frühzeitiges Erkennen ist für die Behandlung des ARDS entscheidend (Infobox 2). Der wichtigste Eckpfeiler der multimodalen ARDS-Therapie ist die lungenprotektive Beatmung zur Vermeidung beatmungsassoziierter Lungenschäden. In Studien wurde hierfür eine Senkung der Mortalität nachgewiesen [62]. Die lungenprotektive Beatmung umfasst niedrige Tidalvolumina ( $\leq 6 \mathrm{ml} / \mathrm{kgKG}$ ) zur Reduktion von Scherkräften auf die Alveolen sowie einen niedrigen Spitzendruck $\left(<30 \mathrm{cmH}_{2} \mathrm{O}\right)$ zur Vermeidung eines Barotraumas.

Die lungenprotektive Beatmung umfasst niedrige Tidalvolumina ( $\leq 6 \mathrm{ml} / \mathrm{kg}$ Standard-KG) und einen niedrigen Spitzendruck ( $\left.<30 \mathrm{cmH}_{2} \mathrm{O}\right)$.

Uneinigkeit herrscht nach wie vor über die Höhe des „idealen PEEP“ (positiver endexspiratorischer Druck). Trotz verbesserter Oxygenierung unter einem höheren

\begin{tabular}{|c|c|}
\hline \multicolumn{2}{|c|}{ Berlin-Definition des ARDS (2012) [61]. } \\
\hline Zeitraum & $\begin{array}{l}\text { innerhalb einer Woche nach einem akuten Ereignis } \\
\text { oder nach neu aufgetretenen bzw. verschlechterten } \\
\text { respiratorischen Symptomen }\end{array}$ \\
\hline Bildgebung & $\begin{array}{l}\text { beidseitige Verdichtungen im Röntgen-Thorax oder CT- } \\
\text { Thorax, die sich nicht allein durch Erguss, Pneumothorax } \\
\text { oder Rundherde erklären lassen }\end{array}$ \\
\hline Ursache des Ödems & $\begin{array}{l}\text { die respiratorische Insuffizienz ist nicht allein durch eine } \\
\text { akute Herzinsuffizienz oder Volumenüberladung erklär- } \\
\text { bar, bei fehlenden Risikofaktoren ist ein objektives Unter- } \\
\text { suchungsverfahren (z. B. Echokardiografie) erforderlich, } \\
\text { um ein hydrostatisches Lungenödem auszuschließen }\end{array}$ \\
\hline Oxygenierung & $\begin{array}{l}\text { es werden } 3 \text { Schweregrade unterschieden: } \\
\text { - mildes ARDS: } \mathrm{PaO}_{2} / \mathrm{FiO}_{2} 201-300 \mathrm{mmHg} \text { und } \\
\\
\text { PEEP/CPAP } \geq 5 \mathrm{cmH}_{2} \mathrm{O} \\
\text { - moderates ARDS: } \mathrm{PaO}_{2} / \mathrm{FiO}_{2} 101-200 \mathrm{mmHg} \text { und } \\
\\
\text { PEEP } \geq 5 \mathrm{cmH}_{2} \mathrm{O} \\
\text { - schweres } \mathrm{ARDS}: \mathrm{PaO}_{2} / \mathrm{FiO}_{2} \leq 100 \mathrm{mmHg} \text { und } \\
\\
\text { PEEP } \geq 5 \mathrm{cmH}_{2} \mathrm{O}\end{array}$ \\
\hline
\end{tabular}

PEEP-Niveau wurde kein Unterschied bei der Krankenhausmortalität zwischen höheren und niedrigeren PEEP-Niveaus nachgewiesen $[63,64]$. Letztlich ist eine individuelle Einstellung des PEEP erforderlich, eine Hilfestellung für den klinischen Alltag bietet die PEEPTabelle des ARDS-Networks (Tab.3).

Bei der Oxygenierung strebt man einen $\mathrm{PaO}_{2}$ von 55-80 mmHg bzw. eine Sauerstoffsättigung zwischen 88 und $95 \%$ an, wobei eine permissive Hyperkapnie $(\mathrm{pH}>7,2)$ toleriert wird. Die Atelektasenbildung in den dorsobasalen Lungenabschnitten und somit die Ausbildung von Rechts-links-Shunts wird durch eine Bauchlagerung des Patienten reduziert. Auch für die Bauchlagerung ist eine mortalitätssenkende Wirkung nachgewiesen [65]. Man sollte sie frühzeitig und ausreichend lange anwenden (mindestens 16 Stunden).

Eine frühzeitige Bauchlagerung führt bei ARDS-

Patienten zu einer Reduktion der Mortalität.

\section{Tabelle 3}

PEEP-Tabelle des ARDS Network.

\begin{tabular}{|lcccccccc}
\hline $\mathrm{FiO}_{2}$ & 0,3 & 0,4 & 0,5 & 0,6 & 0,7 & 0,8 & 0,9 & 1,0 \\
\hline $\mathrm{PEEP}\left(\mathrm{cmH}_{2} \mathrm{O}\right)$ & 5 & $5-8$ & 8 & 10 & $10-14$ & 14 & $14-18$ & $18-24$ \\
\hline
\end{tabular}




\section{Infobox 2}

Eckpfeiler der ARDS-Therapie

- frühzeitiges Erkennen und Behandeln der Ursache (Infektion, Intoxikation, autoimmunes Geschehen)

- lungenprotektive Beatmung: niedrige Tidalvolumina ( $\leq 6 \mathrm{ml} / \mathrm{kgKG}$ ), niedriger Spitzendruck $\left(<30 \mathrm{cmH}_{2} \mathrm{O}\right)$
- frühzeitige Bauchlagerung (>16 Stunden)

- Anwendung von PEEP

- restriktive Infusionstherapie

- ggf. inhalative Gabe von Stickstoffmonoxid

In Einzelfällen kann man den Einsatz von Stickstoffmonoxid (NO), einer Hochfrequenzoszillationsbeatmung (HFOV) oder einer Muskelrelaxation erwägen, eine Empfehlung gibt es für diese Therapieansätze derzeit jedoch nicht.

\section{Extrakorporale Membran- oxygenierung}

Indikation. Wenn trotz optimaler supportiver Therapie eine ausreichende Oxygenierung und/oder $\mathrm{CO}_{2}$-Elimination nicht erzielt werden kann, sollte man den Einsatz eines Lungenersatzverfahrens in Betracht ziehen. Beim ARDS ist die venovenöse extrakorporale Membranoxygenierung (vv-ECMO) das Verfahren der Wahl.

Das Verfahren der Wahl für die extrakorporale Membranoxygenierung beim ARDS ist die venovenöse ECMO.

Die Indikation für eine vv-ECMO ist in folgenden Fällen prinzipiell gegeben (Infobox 3) [66]:

\section{Infobox 3}

Indikationen und Kontraindikationen für eine vv-ECMO

Indikationen:

- schwere Hypoxämie $\left(\mathrm{PaO}_{2} / \mathrm{FiO}_{2}\right.$ $<80 \mathrm{mmHg}$, trotz erhöhtem PEEP)

- Hyperkapnie mit dekompensierter respiratorischer Azidose $(\mathrm{pH}<7,2)$

- nichtprotektive Beatmung (Spitzendruck $>32 \mathrm{~cm} \mathrm{H} \mathrm{H}_{2} \mathrm{O}, \mathrm{FiO}_{2}>0,9$, Tidalvolumen $>8 \mathrm{ml} / \mathrm{kg}$ StandardKG)
- ECMO als „bridging to lung transplant"

Kontraindikationen:

- fortgeschrittene maligne Grunderkrankung

- Kontraindikation für eine Antikoagulation (z. B. zerebrale Blutung)

- beschränkter Gefäßzugang

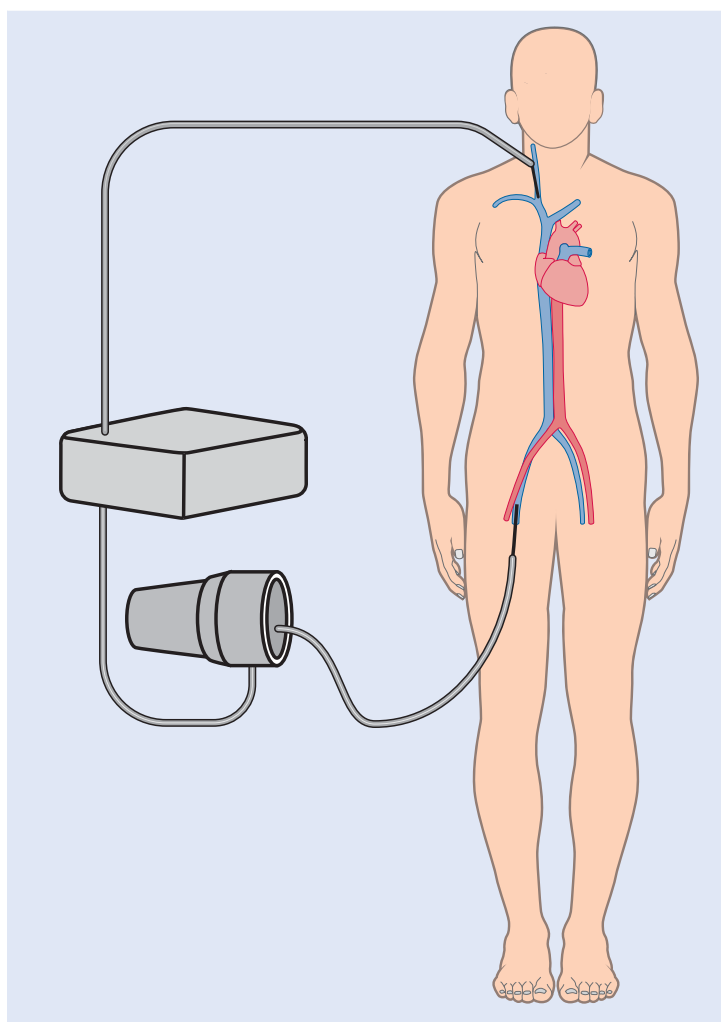

Abb. 1 Venovenöse Membranoxygenierung. Über eine Kanüle in der rechten V. femoralis wird das Blut zum Oxygenator geleitet. Rückgabe des oxygenierten und decarboxylierten Bluts über die rechte V. jugularis interna (mit freundlicher Genehmigung von Dr. med. Olaf Wiesner).

- schwere Hypoxämie $\left(\mathrm{PaO}_{2} / \mathrm{FiO}_{2}<80 \mathrm{mmHg}\right.$, trotz erhöhtem PEEP)

- Hyperkapnie mit dekompensierter respiratorischer Azidose $(\mathrm{pH}<7,2)$

- der nötige Gasaustausch ist nur durch eine nichtprotektive Beatmung zu erzielen (Spitzendruck $>35 \mathrm{cmH}_{2} \mathrm{O}, \mathrm{FiO}_{2}>0,9$, Tidalvolumen $>8 \mathrm{ml} / \mathrm{kgKG}$ )

Kontraindikationen. Kontraindikationen sind eine maligne Grunderkrankung, ein beschränkter Gefäßzugang sowie Kontraindikationen für eine Antikoagulation (z.B. zerebrale Blutungen). Als relative Kontraindikation gilt zudem eine prolongierte und aggressive invasive Beatmung mit hohen Beatmungsdrücken über mehr als 7 Tage.

Praktisches Vorgehen. Um eine ECMO anzulegen, wird eine Kanüle in Seldinger-Technik in die V. femoralis eingebracht (Abb. 1). Über diese großlumige Kanüle wird das Blut zum Oxygenator geleitet. Der Rückfluss des oxygenierten und decarboxylierten Bluts verläuft zentral in der Nähe des rechten Vorhofs, meist über eine Kanüle in der V. jugularis interna. Alternativ ist 


\section{Kasuistik 1}

Ein 48-jähriger Patient ohne bekannte Vorerkrankungen stellte sich Ende Februar mit ausgeprägter Dyspnoe, Husten und Auswurf seit 3 Tagen in der Notaufnahme vor. Bei schnell zunehmender Symptomatik und progredienter Hypoxämie war noch am Aufnahmetag die endotracheale Intubation erforderlich. Im RöntgenThorax-Bild stellten sich beidseits Infiltrate dar. Trotz invasiver Beatmung kam es zu einer weiter fortschreitenden Hypoxämie, eine lungenprotektive Beatmung war nicht mehr möglich.

Therapie. Unter dem klinischen Bild eines schweren ARDS wurde eine venovenöse ECMO angelegt (Abb. 2). Ein in der Notaufnahme durchgeführter InfluenzaSchnelltest war negativ, dennoch wurde bei klinischem Verdacht auf eine Influenza-Pneumonie eine antivirale Therapie mit Oseltamivir (Tamiflu) begonnen. Zur kalkulierten Antibiotikatherapie erhielt der Patient Piperacillin/Tazobactam und Moxifloxacin. Eine Urinuntersuchung auf Legionellen und Pneumokokken fiel negativ aus. Die Bronchoskopie mit BAL ergab den Nachweis von Influenza A(H1N1).

Verlauf. Im Verlauf zeigte sich röntgenologisch ein langsamer Rückgang der Infiltrate und die ECMO-Einstellungen konnten schrittweise reduziert werden.

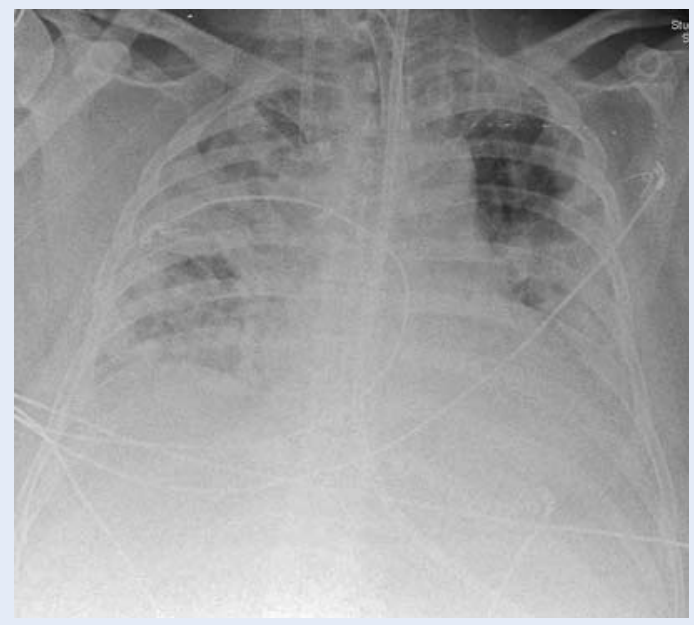

Abb. 2 Patient mit schwerer Influenza-Pneumonie. Röntgenbild an Tag 3 nach vv-ECMO-Implantation.

Nach insgesamt 8 Tagen wurde die vv-ECMO beendet. Bei zu erwartendem prolongiertem Weaning wurde eine perkutane Dilatationstracheotomie angelegt. Die weitere Entwöhnung gestaltete sich komplikationslos und nach 12 Tagen auf der Intensivstation konnte der Patient auf die Normalstation verlegt werden. auch die Implantation einer Doppellumenkanüle in die V. jugularis interna möglich, welche die Mobilisierung des Patienten erlaubt. Gesteuert wird die Oxygenierung hauptsächlich über den Blutfluss. Um eine ausreichende Oxygenierung zu gewährleisten, ist in der Regel ein Blutfluss von mindestens 60\% des Herzzeitvolumens erforderlich (ca. $50-60 \mathrm{ml} / \mathrm{kgKG} / \mathrm{min}$ ). Die periphere Sauerstoffsättigung sollte zwischen 88 und 95\% liegen [67].

Stellenwert. Die ECMO ist mittlerweile eine etablierte Therapie in der Intensivmedizin und die Studienlage belegt, dass sie die Mortalität beim ARDS senken kann
[68]. Diese Aussage wurde insbesondere 2009 bestätigt, als während der Influenza-A(H1N1)-Pandemie der Einsatz der ECMO dramatisch anstieg und zu einer signifikanten Mortalitätsreduktion führte [69].

Interessenkonflikt: Die Autoren geben an, dass kein Interessenkonflikt besteht. 


\section{Kernaussagen}

- Virusinfektionen der unteren Atemwege sind auf der Intensivstation häufig und können zu schweren Krankheitsverläufen führen. Vor allem in der kalten Jahreszeit sowie bei Risikopatienten, insbesondere unter Immunsuppression, sollte man an eine Virusinfektion denken.

- Bei der Diagnostik schwerer Atemwegsinfektionen untersucht man vorzugsweise Proben aus den unteren Atemwegen (BAL, Trachealsekret). Goldstandard ist im intensivmedizinischen Bereich der direkte Virusnachweis mit PCR.

- Bei schweren Influenza-Pneumonien eine antivirale Therapie mit Neuraminidasehemmern (Oseltamivir, Zanamivir) erwägen. Therapiebeginn möglichst innerhalb von 48 Stunden nach Auftreten der Symptome. Mit der InfluenzaImpfung steht eine wirksame Prophylaxe zur Verfügung. Der Einsatz von Kortikosteroiden bei der Influenza-Pneumonie wird nicht empfohlen.
- Eine RSV-Infektion gilt als möglicher Risikofaktor für eine Abstoßungsreaktion bei lungentransplantierten Patienten. Kleine Studien legen den Verdacht nahe, dass eine Therapie mit Ribavirin das Risiko für eine Abstoßungsreaktion reduzieren kann.

- Das Middle East Respiratory Syndrome wird vom MERS-Coronavirus ausgelöst. Neben einer Pneumonie kommt es häufig zu einem akuten Nierenversagen. Dromedare scheinen die Quelle für die zoonotischen Infektionen zu sein. Bei Reisenden aus den arabischen Risikogebieten muss an eine solche Infektion gedacht werden.

- Bei den Viren der Herpesgruppe unterscheidet man zwischen einer Infektion und einer klinisch relevanten Erkrankung. Der mechanische Reiz durch eine Intubation und mechanische Beatmung scheint eine Herpes-simplex-Reaktivierung zu begünstigen.
- Für die CMV-Diagnostik steht mit dem pp65-Antigen-Test eine weitere Methode zum direkten Virusnachweis zur Verfügung. Bei der Therapie der CMVErkrankung muss man auf toxische Nebenwirkungen der Medikamente achten.

- Essenziell bei der Therapie des akuten Lungenversagens (ARDS) ist die lungenprotektive Beatmung. Diese umfasst niedrige Tidalvolumina ( $\leq 6 \mathrm{ml} / \mathrm{kgKG}$ ) und einen niedrigen Spitzendruck ( $<30 \mathrm{cmH}_{2} \mathrm{O}$ ). Die Mortalität des ARDS senken kann zudem eine frühzeitige und ausreichend lange Bauchlagerung des Patienten.

- Das Verfahren der Wahl für eine extrakorporale Membranoxygenierung beim ARDS ist die venovenöse ECMO. Indikationen sind eine schwere Hypoxämie, eine Hyperkapnie mit dekompensierter respiratorischer Azidose oder eine nichtprotektive Beatmung.

\section{Über die Autoren}

\section{Nora Drick}

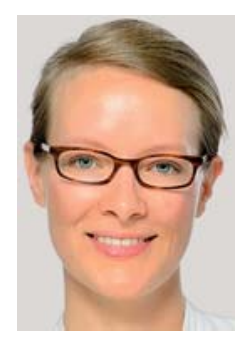

Dr. med. Jahrgang 1985. 2005-2012

Medizinstudium an der Georg-

August-Universität Göttingen. 2012

Promotion. Seit 2012 Assistenzärztin an der Klinik für Pneumologie der Medizinischen Hochschule Hannover.

\section{Tobias Welte}

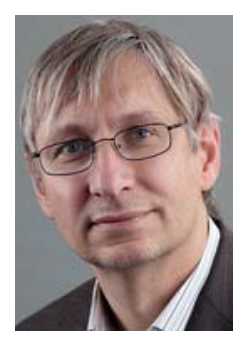

Prof. Dr. med. Jahrgang 1959. 19781985 Studium der Humanmedizin in Hannover. 1985-1994 Ausbildung zum Internisten und Pneumologen in Lehrte und Hannover. 1994-2004 Bereichsleiter für Pneumologie und Intensivmedizin an der Universität Magdeburg. Seit 2004 Direktor der Klinik für Pneumologie der Medizini- schen Hochschule Hannover. Präsident der Deutschen Sepsisgesellschaft, Präsident der Deutschen Gesellschaft für Internistische Intensiv- und Notfallmedizin, Präsidiumsmitglied der Deutschen Interdisziplinären Gesellschaft für Intensivmedizin.

\section{Korrespondenzadresse}

Dr. med. Nora Drick

Klinik für Pneumologie

Medizinische Hochschule Hannover

Carl-Neuberg-Str. 1

30625 Hannover

E-Mail: Drick.Nora@mh-hannover.de

\section{Literatur}

1 Luyt CE. Virus diseases in ICU patients: a long time underestimated; but be aware of overestimation. Intensive Care Med 2006; 32: $968-970$

2 Lieberman D, Lieberman D, Gelfer Y et al. Pneumonic vs nonpneumonic acute exazerbations of COPD. Chest 2002; 122: $1264-1270$

3 Atmar RL, Guy E, Guntupalli KK et al. Respiratory tract viral infections in inner-city asthmatic adults. Arch Intern Med 1998; 158: $2453-2459$ 
4 de Roux A, Marcos MA, Garcia E et al. Viral communityacquired pneumonia in nonimmunocompromised adults. Chest 2004; 125: $1343-1351$

5 Glezen WP, Greenberg SB, Atmar RL et al. Impact of respiratory virus infections on persons with chronic underlying conditions. JAMA 2000; 283: 499-505

6 Herold S, Becker C, Ridge KM et al. Influenza virus-induced lung injury: pathogenesis and implications for treatment. Eur Respir ] 2015; 45: $1463-1478$

7 Choi SH, Hong SB, Ko GB et al. Viral infection in patients with severe pneumonia requiring intensive care unit admission. Am J Respir Crit Care Med 2012; 186: 325-332

8 Hong HL, Hong SB, Ko GB et al. Viral infection is not uncommon in adult patients with severe hospital-acquired pneumonia. PLoS One 2014; 9: e95865

9 Daubin C, Parienti JJ, Vincent S et al. Epidemiology and clinical outcome of virus-positive respiratory samples in ventilated patients: a prospective cohort study. Crit Care 2006; 10: R142

10 Thompson WW, Shay DK, Weintraub E et al. Mortality associated with influenza and respiratory syncytial virus in the United States. JAMA 2003; 289: 179-186

11 Robert Koch Institut. Aktualisierung der der Influenza zugeschriebenen Mortalität bis einschließlich der Saison 2012/2013. Epid Bull 2015; 3: 1 - 8

12 Catania J, Que LG, Govert JA et al. High Intensive Care Unit Admission Rate for 2013-2014 Influenza Is Associated with a Low Rate of Vaccination. Am J Respir Crit Care Med 2014; 189 : $485-487$

13 Paddock CD, Liu L, Denison AM et al. Myocardial injury and bacterial pneumonia contribute to the pathogenesis of fatal influenza B virus infection. J Infect Dis 2012; 205: 895-905

14 Robert Koch Institut. Ratgeber für Ärzte: Influenza (Saisonale Influenza, Influenza A(H1N1) 2009, Aviäre Influenza). Stand $12 / 2013$

15 Robert Koch Institut. Impfempfehlungen der Ständigen Impfkommission (STIKO) am Robert Koch-Institut/Stand: August 2014. Epid Bull 2014; 34: 305 - 340

16 Carrat F, Vergu E, Ferguson NM et al. Time lines of infection and disease in human influenza: a review of volunteer challenge studies. Am J Epidemiol 2008; 167: 775-785

17 Memoli MJ, Athota R, Reed S et al. The natural history of influenza infection in the severly immunocompromised vs nonimmunocompromised hosts. Clin Infect Dis 2014; 58: 214

18 Jefferson $T$, Jones $M$, Doshi $P$ et al. Oseltamivir for influenza in adults and children: systematic review of clinical study reports and summary of regulatory comments. BMJ 2014; 348: g2545

19 Dobson J, Whitley RJ, Pocock S et al. Oseltamivir treatment for influenza in adults: a meta-analysis of randomised controlled trials. Lancet 2015; 385: 1729-1737

20 Muthuri SG, Venkatesan S, Myles PR et al. Effectiveness of neuraminidase inhibitors in reducing mortality in patients admitted to hospital with influenza A H1N1pdm09 virus infection: a meta-analysis of individual participant data. Lancet Respir Med 2014; 2: 395-404

21 Martin-Loeches I, Lisboa T, Rhodes A et al. Use of early corticosteroid therapy on ICU admission in patients affected by severe pandemic ( $11 \mathrm{~N} 1) v$ influenza $A$ infection. Intensive Care Med 2011; 37: 272-283

22 Brun-Buisson C, Richard JC, Mercat A et al. Early corticosteroids in severe influenza $\mathrm{A} / \mathrm{H} 1 \mathrm{~N} 1$ pneumonia and acute respi- ratory distress syndrome. Am J Respir Crit Care Med 2011; 183: $1200-1206$

23 Lee N, Lui GC, Wong KT et al. High morbidity and mortality in adults hospitalized for respiratory syncytial virus infections. Clin Infect Dis 2013; 57: 1069-1077

24 McColl MD, Corser RB, Bremner J et al. Respiratory syncytial virus infection in adult BMT recipients: effective therapy with short duration nebulised ribavirin. Bone Marrow Transplant 1998; 21: $423-425$

25 Kumar D, Erdman D, Keshavjee S et al. Clinical impact of community-acquired respiratory viruses on bronchiolitis obliterans after lung transplant. Am J Transplant 2005; 5: 2031 2036

26 Fuehner T, Dierich M, Duesberg C et al. Single-centre experience with oral ribavirin in lung transplant recipients with paramyxovirus infections. Antivir Ther 2011; 16: 733 - 740

27 de Fontbrune FS, Robin M, Porcher R et al. Palivizumab treatment of respiratory syncytial virus infection after allogeneic hematopoietic stem cell transplantation. Clin Infect Dis 2007; 45: 1019-1024

28 Boivin G, Abed Y, Pelletier G et al. Virological features and clinical manifestations associated with human metapneumovirus: A new paramyxovirus responsible for acute respiratorytract infections in all age groups. J Infect Dis 2002; 186: $1330-1334$

29 Sumino KC, Agapov E, Pierce RA et al. Detection of severe human metapneumovirus infection by real-time polymerase chain reaction and histopathological assessment. J Infect Dis 2005; 192: 1052

30 Wyde PR, Chetty SN, Jewell AM et al. Comparison of the inhibition of human metapneumovirus and respiratory syncytial virus by ribavirin and immune serum globulin in vitro. Antiviral Res 2003; 60: 51

31 Nicholls JM, Poon LL, Lee KC et al. Lung pathology of fatal severe acute respiratory syndrome. Lancet 2003; 361: 1773 1778

32 Chiou HE, Liu CL, Buttrey MJ et al. Adverse effects of ribavirin and outcome in severe acute respiratory syndrome: experience in two medical centers. Chest 2005; 128: $263-272$

33 Donnelly CA, Ghani AC, Leung GM et al. Epidemiological determinants of spread of causal agent of severe acute respiratory syndrome in Hong Kong. Lancet 2003; 361: 1761 1766

34 Leung GM, Hedley AJ, Ho LM et al. The epidemiology of severe acute respiratory syndrome in the 2003 Hong Kong epidemic: an analysis of all 1755 patients. Ann Intern Med 2004; 141: $662-673$

35 Robert Koch Institut. SARS-Epidemie im Jahr 2003: Ein Rückblick auf die Aktivitäten des RKI (Teil 1). Epid Bull 2004; 8: $1-8$

36 Hung IF, Cheng VC, Wu AK et al. Viral loads in clinical specimens and SARS manifestations. Emerg Infect Dis 2004; 10 : $1550-1557$

37 Guery B, Poissy J, el Mansouf L et al. Clinical features and viral diagnosis of two cases of infection with Middle East Respiratory Syndrome coronavirus: a report of nosocomial transmission. Lancet 2013; 381: 2265

38 Assiri A, Al-Tawfiq JA, Al-Rabeeah AA et al. Epidemiological, demographic, and clinical characteristics of 47 cases of Middle East respiratory syndrome coronavirus disease from 
Saudi Arabia: a descriptive study. Lancet Infect Dis 2013; 13 : $752-761$

39 Falzarano $D$, de Wit E, Rasmussen AL et al. Interferon- $\alpha 2 b$ and ribavirin treatment improves outcome in MERS-CoV-infected rhesus macaques. Nat Med 2013; 19: $1313-1317$

40 Omrani AS, Saad MM, Baig K et al. Ribavirin and interferon alfa-2a for severe Middle East respiratory syndrome coronavirus infection: a retrospective cohort study. Lancet Infect Dis 2014; 14: 1090 - 1095

41 Al-Tawfiq JA, Momattin H, Dib J et al. Ribavirin and interferon therapy in patients infected with the Middle East respiratory syndrome coronavirus: an observational study. Int J Infect Dis 2014; 20: $42-46$

42 Ison MG. Adenovirus infections in transplant recipients. Clin Infect Dis 2006; 43: 331

43 Ohori NP, Michaels MG, Jaffe R et al. Adenovirus pneumonia in lung transplant recipients. Hum Pathol 1995; 26: 1073 - 1079

44 Doan ML, Mallory GB, Kaplan SL et al. Treatment of adenovirus pneumonia with cidofovir in pediatric lung transplant recipients. J Heart Lung Transplant 2007; 26: $883-889$

45 Ljungman P, Ribaud P, Eyrich M et al. Cidofovir for adenovirus infections after allogeneic hematopoietic stem cell transplantation: a survey by the Infectious Diseases Working Party of the European Group for Blood and Marrow Transplantation. Bone Marrow Transplant 2003; 31: 481-486

46 Cook CH, Martin LC, Yenchar JK et al. Occult herpes family viral infections are endemic in critically ill surgical patients. J Med Virol 2004; 72: 121-125

47 Bruynseels P, Jorens PG, Demey HE et al. Herpes simplex virus in the respiratory tract of critical care patients: a prospective study. Lancet 2003; 362: 1536 - 1541

48 Hunt DP, Muse VV, Pitman MB. Case records of the Massachusetts General Hospital. Case 12-2013. An 18-year-old woman with pulmonary infiltrates and respiratory failure. N Engl J Med 2013; 368: 1537-1534

49 Ong GM, Lowry K, Mahajan S et al. Herpes simplex type 1 shedding is associated with reduced hospital survival in patients receiving assisted ventilation in a tertiary referral intensive care unit. J Med Virol 2004; 72: 121-125

50 Engelmann I, Gottlieb J, Meier A et al. Clinical relevance of and risk factors for HSV-related tracheobronchitis or pneumonia: results of an outbreak investigation. Crit Care 2007; 11: R119

51 Jaber S, Chanques G, Borry J et al. Cytomegalovirus infection in critically ill patients: associated factors and consequences. Chest 2005; 127: $233-241$

52 De Jong MD, Galasso GJ, Gazzard B et al. Summary of the II International Symposium on Cytomegalovirus. Antiviral Res 1998; 39: $141-162$

53 Kotton CN, Kumar D, Caliendo AM et al. International consensus guidelines on the management of cytomegalovirus in solid organ transplantation. Transplantation 2010; 89: 779795

54 Maschmeyer G, Carratalà J, Buchheidt D et al. Diagnosis and antimicrobial therapy of lung infiltrates in febrile neutropenic patients (allogeneic SCT excluded): updated guidelines of the Infectious Diseases Working Party (AGIHO) of the German Society of Hematology and Medical Oncology (DGHO). Ann Oncol 2015; 26: 21-33
55 Höffken G, Lorenz J, Kern W et al. Epidemiologie, Diagnostik, antimikrobielle Therapie und Management von erwachsenen Patienten mit ambulant erworbenen unteren Atemwegsinfektionen sowie ambulant erworbener Pneumonie - Update 2009, S3-Leitlinie der Paul-Ehrlich-Gesellschaft für Chemotherapie, der Deutschen Gesellschaft für Pneumologie und Beatmungsmedizin, der Deutschen Gesellschaft für Infektiologie und vom Kompetenznetzwerk CAPNETZ. Pneumologie 2009; 63: e1-e68

56 Matar LD, McAdams HP, Palmer SM et al. Respiratory viral infections in lung transplant recipients: radiologic findings with clinical correlation. Radiology 1999; 213: 735 - 742

57 Mandell LA, Wunderink RG, Anzueto A et al. Infectious Diseases Society of America/American Thoracic Society consensus guidelines on the management of community-acquired pneumonia in adults. Clin Infect Dis 2007; 1: 44

58 Rello J, Rodríguez A, Ibañez P et al. Intensive care adult patients with severe respiratory failure caused by Influenza A (H1N1)v in Spain. Crit Care 2009; 13: R148

59 Falagas ME, Bliziotis IA. Pandrug-resistant Gram-negative bacteria: the dawn of the post-antibiotic era? Int J Antimicrob Agents 2007; 29: 630-636

60 Goldmann A, Weber-Carstens S, Buchholz U. Bericht vom ARDS-Netzwerk zum Monitoring schwerer Lungenerkrankungen durch Influenza in der Saison 2012/2013. Epidemiologisches Bulletin 2014; 13: $103-106$

61 Ranieri VM, Rubenfeld GD, Thompson BT et al. Acute respiratory distress syndrome: the Berlin Definition. JAMA 2012; 307 : 2526-2533

62 The Acute Respiratory Distress Syndrome Network. Ventilation with lower tidal volumes as compared with traditional tidal volumes for acute lung injury and the acute respiratory distress syndrome. N Engl J Med 2000; 342: 1301 - 1308

63 Brower RG, Lanken PM, Maclntyre N et al. Higher versus lower positive end-expiratory pressures in patients with the acute respiratory distress syndrome. NEJM 2004; 351: 327-336

64 Meade MO, Cook DJ, Guyatt GH et al. Ventilation strategy using low tidal volumes, recruitment maneuvers, and high positive end-expiratory pressure for acute lung injury and acute respiratory distress syndrome: a randomized controlled trial. JAMA 2008; 299: 637-645

65 Guérin C, Reignier J, Richard JC et al. Prone positioning in severe acute respiratory distress syndrome. $\mathrm{N}$ Engl J Med 2013; 368: 2159-2168

66 Extracorporeal Life Support Organization (ESLO). ESLO Guidelines for Adult Respiratory Failure. Im Internet: https://www. elso.org/Resources/Guidelines.aspx

67 Richard C, Argaud L, Blet A et al. Extracorporeal life support for patients with acute respiratory distress syndrome: report of a Consensus Conference. Ann Intensive Care 2014; 4: 15

68 Peek G], Mugford M, Tiruvoipati R et al. Efficacy and economic assessment of conventional ventilatory support versus extracorporeal membrane oxygenation for severe adult respiratory failure (CESAR): a multicentre randomised controlled trial. Lancet 2009; 374: $1351-1363$

69 Noah MA, Peek G], Finney SJ et al. Referral to an extracorporeal membrane oxygenation center and mortality among patients with severe 2009 influenza A(H1N1). JAMA 2011; 306: 1659 1668 


\section{CME-Fragen}

\section{CME.thieme.de}

\section{CME-Teilnahme}

- Viel Erfolg bei Ihrer CME-Teilnahme unter http://cme.thieme.de

- Diese Fortbildungseinheit ist 12 Monate online für eine CME-Teilnahme verfügbar.

- Sollten Sie Fragen zur Online-Teilnahme haben, unter

http://cme.thieme.de/hilfe finden Sie eine ausführliche Anleitung.

\section{1}

Welche Aussage zum pp65-Test ist richtig?
A Der pp65-Test gehört zu den indirekten Nachweisverfahren.
B Der Nachweis von pp65 spricht für eine latente Herpes-simplex-Infektion.
C Ein Anstieg des pp65-Antigens weist auf replizierende CMV-Viren hin.
D Die Leukozytenzahl im Blut hat keinen Einfluss auf das Ergebnis des Tests.
E Der pp65-Test hat die PCR als diagnostischen Test fast vollständig ersetzt.

\section{2}

Welche Aussage zur lungenprotektiven Beatmung ist richtig?
A Die Tidalvolumina der lungenprotektiven Beatmung richten sich nach dem tatsächlichen Gewicht des Patienten.

B Sie umfasst einen hohen PEEP (20 - 25 mbar).

C Die lungenprotektive Beatmung beinhaltet die inhalative Gabe von Stickstoffmonoxid.

D Sie umfasst einen Spitzendruck von unter $30 \mathrm{cmH}_{2} \mathrm{O}$ sowie niedrige Tidalvolumina $(6 \mathrm{ml} / \mathrm{kgKG})$.

E Ein prognostischer Vorteil für die lungenprotektive Beatmung konnte bisher noch nicht nachgewiesen werden.

\section{3}

Welche Aussage zum akuten Lungenversagen (ARDS) ist richtig?
A Die Letalität des ARDS liegt bei ca. 15\%.

B Bei einem $\mathrm{PaO}_{2} / \mathrm{FiO}_{2} \leq 100 \mathrm{mmHg}$ und einem PEEP $\geq 5 \mathrm{~cm} \mathrm{H}_{2} \mathrm{O}$ handelt es sich um ein mildes ARDS.

C Im Röntgenbild der Lunge zeigt das ARDS beidseitige Verdichtungen.

D Der Einsatz von inhalativem Stickstoffmonoxid gehört beim ARDS zu den wichtigsten Therapieoptionen und kann nachweislich die Letalität senken.

E Der optimale PEEP bei der ARDS-Beatmung liegt bei $8 \mathrm{mbar}$.

\section{4}

Welche Aussage zur extrakorporalen Membranoxygenierung (ECMO) ist richtig?
A Bei der venovenösen ECMO gelangt das oxygenierte Blut über eine großlumige Kanüle in der V. femoralis wieder zum Patienten.

B Eine schwere Hypoxämie ist eine der Indikationen für die extrakorporale Membranoxygenierung beim ARDS.

C Eine Antikoagulation ist bei der extrakorporalen Membranoxygenierung nicht erforderlich.

D Eine Mobilisierung ist bei Patienten an der ECMO untersagt.

E Bei der ECMO wird das Blut lediglich oxygeniert, eine Decarboxylierung ist nicht möglich.

\section{5}

Sie behandeln einen immunsupprimierten Patienten mit einer schweren CMV-Reaktivierung. Worauf sollten Sie bei einer i.v. Therapie mit Ganciclovir (Cymeven) insbesondere achten?
A Anstieg des Kreatinins und Neutropenie
B Thrombozytose und Herzrhythmusstörungen
C Reizhusten und Urtikaria
D Rhabdomyolyse und Anstieg der Lipase
E Retinitis und Halluzinationen 


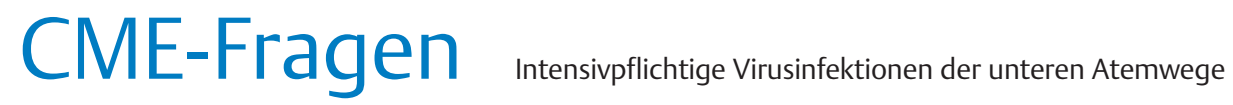

Welche Aussage zu Herpes-simplexViren ist falsch?
A HSV gehören zu den selten auf der Intensivstation nachgewiesenen Viren.
B Aciclovir ist das Mittel der ersten Wahl bei einer HSV-Pneumonie.
C Herpes-Viren können insbesondere bei immunsupprimierten Patienten zu schweren Erkrankungsverläufen führen.
D Herpes-Viren lassen sich mit einer PCR nachweisen.
E Herpes-Viren können nach einer Primärinfektion latent in Ganglien verbleiben.

7

Welche Aussage zu Influenza-Viren und der medikamentösen Therapie einer Infektion ist richtig?
A Für die medikamentöse Therapie der Influenza-Pneumonie werden primär M2-Kanal-Blocker (Amantadin) empfohlen.

B Influenza-Viren zeichnen sich durch eine ausgeprägte genetische Stabilität aus.

C Resistenzen gegen Oseltamivir (Neuraminidasehemmer) sind bisher nicht bekannt.

D Das pandemische Influenza-Virus A(H1N1)2009 trat kurzzeitig während der Pandemie 2009 auf.

E Die Wirksamkeit einer Therapie mit Oseltamivir hängt wesentlich vom Zeitpunkt des Therapiebeginns ab.

\section{8}

Welche Aussage zur Diagnostik viraler Infektionen auf der Intensivstation ist richtig?
A Goldstandard ist nach wie vor der indirekte Virusnachweis mit Antikörperserologie.
B Aufgrund der niedrigen Sensitivität wird die PCR für den Nachweis respiratorischer Viren nur noch selten eingesetzt.
C Insbesondere bei immunsupprimierten Patienten mit unklarer Infektionserkrankung sollte man eine virologische Diagnostik durchführen.
D Für die Diagnostik respiratorischer Virusinfektionen sollte man einen Nasen-Rachen-Abstrich gewinnen.
E Das Thorax-Röntgenbild zeigt bei einer Viruspneumonie spezifische Veränderungen.

\section{9}

Welche therapeutischen Maßnahmen können beim akuten Lungenversagen (ARDS) nachweislich die Letalität reduzieren?

\section{0}

Welche Aussage zum Respiratory Syncytial Virus (RSV) ist falsch?
A Bauchlagerung und lungenprotektive Beatmung
B lungenprotektive Beatmung und hoher PEEP
C PEEP $\geq 20 \mathrm{~cm} \mathrm{H}_{2} \mathrm{O}$ und Bauchlagerung
D forcierte Volumengabe und lungenprotektive Beatmung
E hoher PEEP und Muskelrelaxation

A RSV-Infektionen treten vor allem in der kalten Jahreszeit auf.

B RSV ist einer der bedeutendsten Erreger respiratorischer Infektionen bei Säuglingen und Kleinkindern.

C Bei stammzell- und lungentransplantierten Patienten kann das RSV zu schweren Erkrankungen führen.

D Der therapeutische Einsatz von Palivizumab, einem monoklonaler Antikörper gegen das RS-Virus, wird insbesondere bei Erwachsenen empfohlen.

E Die Therapie ist überwiegend supportiv. 